AperTO - Archivio Istituzionale Open Access dell'Università di Torino

\title{
A tool for semi-automatic linear feature detection based on DTM
}

\section{This is the author's manuscript}

Original Citation:

Availability:

This version is available http://hdl.handle.net/2318/154332

since 2018-06-15T14:59:34Z

Published version:

DOI:10.1016/j.cageo.2014.10.005

Terms of use:

Open Access

Anyone can freely access the full text of works made available as "Open Access". Works made available under a Creative Commons license can be used according to the terms and conditions of said license. Use of all other works requires consent of the right holder (author or publisher) if not exempted from copyright protection by the applicable law. 
This Accepted Author Manuscript (AAM) is copyrighted and published by Elsevier. It is posted here by agreement between Elsevier and the University of Turin. Changes resulting from the publishing process - such as editing, corrections, structural formatting, and other quality control mechanisms - may not be reflected in this version of the text. The definitive version of the text was subsequently published in COMPUTERS \& GEOSCIENCES, 75, 2015, 10.1016/j.cageo.2014.10.005.

You may download, copy and otherwise use the AAM for non-commercial purposes provided that your license is limited by the following restrictions:

(1) You may use this AAM for non-commercial purposes only under the terms of the CC-BY-NC-ND license.

(2) The integrity of the work and identification of the author, copyright owner, and publisher must be preserved in any copy.

(3) You must attribute this AAM in the following format: Creative Commons BY-NC-ND license (http://creativecommons.org/licenses/by-nc-nd/4.0/deed.en), 10.1016/j.cageo.2014.10.005

The publisher's version is available at:

http://linkinghub.elsevier.com/retrieve/pii/S0098300414002283

When citing, please refer to the published version.

Link to this full text:

http://hdl.handle.net/2318/154332 


\section{Elsevier Editorial System(tm) for Computers \& Geosciences Manuscript Draft}

Manuscript Number:

Title: A Tool for Semi-Automatic Geostructural Survey Based on DTM

Article Type: Research Article

Keywords: Geological structure, Lineament, DTM, Semi-Automatic extraction, Monferrato

Corresponding Author: Mrs. Gessica Umili, PhD

Corresponding Author's Institution: Università degli Studi di Parma

First Author: Sabrina Bonetto, PhD

Order of Authors: Sabrina Bonetto, PhD; Anna Facello, PhD; Anna Maria Ferrero, Associate Professor; Gessica Umili, PhD

Abstract: The tectonic movement along faults is often reflected by characteristic geomorphological features such as linear valleys, ridgelines and slope-breaks, steep slopes of uniform aspect, regional anisotropy and tilt of terrain. In the last years, the remote sensing data has been used as a source of information for the detection of tectonic structures. In this paper, a new approach for semi-automatic extraction and characterization of geological lineaments is presented. The overall positive aspects of this semi-automatic process were found to be the rapidity of preliminary assessment, the possibility to identify the most interesting portions to be investigated and to analyze zones that are not directly accessible. This method has been applied to a geologically well-known area (the Monferrato geological domain) in order to validate the results of the software processing with literature data. Results obtained are discussed and preliminary remarks are put forward.

Suggested Reviewers: Katsuaki Koike

Kumamoto University

koike@gpo.kumamoto-u.ac.jp

He's an expert in the field of lineament detection

Herbert Henkel

Department of Land and Water Resources Engineering, Royal Institute of Technology of Stockholm herbert@kth.se

He's an expert in the field of lineament detection

Gyozo Jordan

Institute for Geochemical Research of Budapest

gyozojordan@gmail.com

He's an expert in the field of lineament detection 


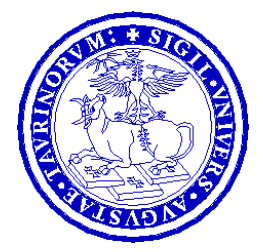

\section{UNIVERSITA’ DEGLI STUDI DI TORINO \\ DIPARTIMENTO DI SCIENZE DELLA TERRA \\ Via Valperga Caluso, 35 - 10125 TORINO \\ Tel. (011) 670.5148 (centralino) Fax (011) 6705146 \\ Tel. (011) 670.5195 (direzione) - (011) 670.5149 (segreteria) \\ Indirizzo e-mail: direzione.dst@unito.it}

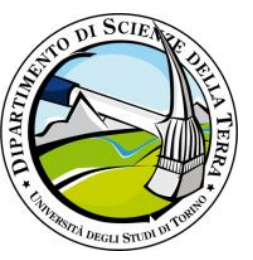

Torino, April 7th 2014

Object: Submission of paper

\section{A Tool for Semi-Automatic Geostructural Survey Based on DTM}

is here proposed for publication by Bonetto Sabrina ${ }^{1}$, Facello Anna ${ }^{2}$, Ferrero Anna Maria ${ }^{1}$, Umili Gessica ${ }^{3}$

${ }^{1}$ Department of Earth Sciences, University of Turin, Valperga Caluso 35, 10125 Turin, Italy.

\{sabrina.bonetto, anna.ferrero\}@unito.it

${ }^{2}$ CNR-IRPI, Strada delle Cacce,73 - 10135 Torino, Italy. anna.facello@irpi.cnr.it

${ }^{3}$ Department of Civil, Environmental and Territory Engineering, University of Parma, Parco Area delle Scienze 181/A, 43124 Parma, Italy. gessica.umili@unipr.it

The paper concerns a new approach for semi-automatic extraction and characterization of geological lineaments.

Hoping that the paper could be of your interest I remain sincerely yours

Dott. Sabrina Bonetto 
Highlights (for review)

\section{Highlights:}

- A new semi-automatic approach for extraction of geological lineaments is presented

- CurvaTool code has been applied to DTMs of Monferrato domain

- Main lineament systems have been correctly identified by semi-automatic processing

- Good correspondence between literature data and CurvaTool results was found 


\section{A Tool for Semi-Automatic Geostructural Survey Based on DTM Bonetto Sabrina $^{\text {a }}$, Facello Anna ${ }^{\mathrm{b}}$, Ferrero Anna Maria ${ }^{\mathrm{a}}$, Umili Gessica ${ }^{\mathrm{c}}$}

${ }^{a}$ Department of Earth Sciences, University of Turin, Valperga Caluso 35, 10125 Turin, Italy. \{sabrina.bonetto, anna.ferrero\}@unito.it

${ }^{\mathrm{b}}$ CNR-IRPI, Strada delle Cacce,73 - 10135 Torino, Italy. anna.facello@irpi.cnr.it

${ }^{\mathrm{c}}$ Department of Civil, Environmental and Territory Engineering, University of Parma, Parco Area delle Scienze 181/A, 43124 Parma, Italy. gessica.umili@unipr.it

Corresponding author: Gessica Umili, Department of Civil, Environmental and Territory Engineering, University of Parma, Parco Area delle Scienze 181/A, 43124 Parma, Italy. gessica.umili@unipr.it

Abstract. The tectonic movement along faults is often reflected by characteristic geomorphological features such as linear valleys, ridgelines and slope-breaks, steep slopes of uniform aspect, regional anisotropy and tilt of terrain. In the last years, the remote sensing data has been used as a source of information for the detection of tectonic structures. In this paper, a new approach for semi-automatic extraction and characterization of geological lineaments is presented. The overall positive aspects of this semi-automatic process were found to be the rapidity of preliminary assessment, the possibility to identify the most interesting portions to be investigated and to analyze zones that are not directly accessible. This method has been applied to a geologically well-known area (the Monferrato geological domain) in order to validate the results of the software processing with literature data. Results obtained are discussed and preliminary remarks are put forward.

Keywords: Geological structure, Lineament, DTM, Semi-Automatic extraction, Monferrato

\section{Highlights}

- A new semi-automatic approach for extraction of geological lineaments is presented

- CurvaTool code has been applied to DTMs of Monferrato domain

- Main lineament systems have been correctly identified by semi-automatic processing

- Good correspondence between literature data and CurvaTool results was found 


\section{Introduction}

In the field of geology satellite remotely sensed data have been used as source of information for the detection of tectonic structures such as faults, large-scale fractures, and fracture zones (Wladis, 1999; Morelli and Piana, 2006; Hashim et al, 2013). Geological lineaments are elements that can be used in assisting mineral prospecting, hydrogeology studies, tectonic studies for the delineation of major structural units, analysis of structural deformation patterns and identification of geological boundaries. Lineament maps created by means of conventional field mapping techniques cannot identify all the lineaments existing in the area, due to the enlarged scale and reduced view/scope of the mapper. In contrast, remote sensing, with progressive development in the image enhancement techniques, is an opportunity to prepare relatively more reliable and comprehensive lineament maps.

Normally, geological lineaments can be detected due to their geomorphological features, such as morphotectonic elements, drainage network offsets and stream segment alignments, and/or spectral criterion, such as tonal change, pattern and textures, using (stereo-) aerial photographs and other remotely sensed imagery. In literature the extraction of geological lineaments from images can be grouped into three main approaches: (i) manual extraction (Jordan and Schott, 2005), (ii) semi-automatic extraction (Lim et al., 2001; Jordan et al., 2005), and (iii) automatic extraction (Masoud and Koike, 2011; Saadi et al., 2011). Manual and semi-automatic approaches are greatly influenced by the experience of the analyst, while automatic extraction depends on the algorithms efficiency and on the information content in the image (Hashim et al, 2013, Casas et al., 2000, Ekneligoda and Henkel, 2006). The automatic extraction of lineaments from satellite images normally includes the determination of their orientation and density.

In recent years, space-borne satellite and high altitude aircraft images and their products, such as Digital Terrain Models (DTM), have been providing observations of geological lineaments and their relationships to nearby geomorphic and geologic features that are not easily apparent from the ground through onsite field mapping. Furthermore, field work is a costly and sometimes dangerous undertaking, and any technique that can make field work more efficient is thus beneficial. Digital Terrain Models (DTM) have been used as shaded relief models either alone or in combination with remotely sensed images on a regional scale. Moreover, three-dimensional view with image drape and digital cross sections have been used for morphotectonic investigations (Jordan et al., 2005). A DTM can be used to estimate the 3-D orientation of bedding planes and, consequently, to identify high frequency topographic lineaments. In literature, estimated bedding plane dip directions are shown to be accurate and reliable when compared with field-based observations, while the dip angles present small errors in the location of a manually digitized lineament. It is likely that small errors in the location of a manually digitized lineament will affect dip estimation more than dip direction estimation, particularly for steeply dipping structures. (Cracknell et al., 2013). In this paper, authors propose the use of an innovative method for the extraction of geological features using a semi-automatic geometrical approach based on DTM. The method will be discussed and presented in the following sections. The overall positive aspects of this semi-automatic process were found to be the rapidity of a preliminary tectonic assessment, the possibility 
to identify the most interesting portions of the area to be investigated and the possibility to analyze zones that are not directly accessible.

Monferrato has been selected as the area-test to verify the software performance in lineaments identification on a small scale DTM. It is a highly deformed geological domain, but is also rife with literature data which are very helpful for a suitable validation of the results in software applications.

Monferrato domain represents, together with Langhe Basin, Turin Hills, Alto Monferrato and Borbera-Gruethree, the tectonicsedimentary domain, different by structural and (or) stratigraphic characteristics, that identify the Tertiary Piedmont Basin (TPB) (Piana, 2000; D’Atri et al., 2002). TPB is located on the suture between Alps and Apennine belts and was generated by post-collisional subsidence next to the Alpine/Apennine orogen. The sedimentation of TPB started at the beginning of Oligocene, during a period of tectonic movement within the western Mediterranean area, including the opening of Ligurian Sea towards south (Gueguen et al., 1998) and the formation, mainly in post Tortonian time, of Apennine thrust belt towards east (Castellarin, 2001). Despite these tectonic events, in TPB there are no major tectonic disturbances (Carrapa and GarciaCastellanos, 2005). The main Miocene subsidence event of TPB has been associated with compressional tectonics, possibly related to the thrust activity developed in the south-western Alps (Gelati and Gnaccolini, 1998; Roure et al., 1990). Evidence of thrust tectonics in the Western Alps, together with Oligocene-Miocene synsedimentary compressional structures in TPB (Carrapa et al., 2003; Hoogerduijn Strating et al., 1991; Schmid and Kissling, 2000) suggest that the basin was mainly undergoing NE-SW to NW-SE, shortening since Oligocene time, while extension played a minor role in the evolution of the basin (Carrapa and Garcia-Castellanos, 2005).

Most of the information about faults trending and their distribution result either from field evidences and small-scale kinematic observations; in other cases they have been verified by geomorphological and spectral analyses with remote sensed imagery (Morelli and Piana, 2006). The stratigraphic succession is composed of a sedimentary sequence mainly characterised by terrigenous deposits. Because of rich vegetation and human activities, the substratum is poorly exposed and a small number of outcroppings is present. Therefore, direct evidences of the structural lineaments are not easily detectable on the field and, sometimes, their presence is just supposed for stratigrafical reasons.

\section{The semi-automatic method}

The method here described to perform a semi-automatic geostructural survey on a DTM is based on the assumption that a geological lineament can be geometrically identified as a convex or concave edge of the surface of a DTM, particularly in presence of a structural control of the geomorphological evolution of the analyzed areas. The method is called semi-automatic because the user is asked for two threshold values, described in the following, in order to choose which edges are significant and therefore have to be extracted. Moreover, the statistical treatment of the results, as presently arranged, requires the user to input expected orientations data of the clusters of lineaments. Furthermore, a manual edit- 
ing phase could be needed in order to obtain a complete and correct map of the lineaments: for example a false lineament could be generated by a group of points whose curvature values are above the fixed threshold, but representing a surface portion with any evident crest or valley. Besides, a lineament could be incomplete if the missing part lays in a portion of surface that in the DTM is smoother than in reality (this could be due to the DTM resolution, see Sec. 2.1).

Therefore an accurate check and editing should be performed by an expert user in order to ensure the reliability of the results.

The first step of this research consisted in the lineaments identification in a geologically well-known area in order to be able to validate the results of the software processing with reliable literature data. Since the structural setting is wellknown, a DTM of the Monferrato domain was chosen: it represents a rectangular area of about $300 \mathrm{~km}^{2}$, with a density of about $400 \mathrm{pts} / \mathrm{km}^{2}$, namely a resolution of about $50 \mathrm{~m}$ (Fig. 1); the total difference in height of the DTM is about 370 $\mathrm{m}$.

Figure 1. DTM of Monferrato (120 084 points, 238722 triangles)

\subsection{CurvaTool software}

The code CurvaTool (Umili et al., 2013) was originally developed to automatically detect edges on DSM (Digital Surface Model) of natural rock mass outcrops, assuming that they represent the discontinuity traces. In this work the code CurvaTool has been applied to DTMs of large portion of territory in order to automatically detect edges which represent potential geological lineaments. As natural outcrops, also the earth surface can have an infinite variety of shapes with different dimensions, but a common characteristic is generally their non-planar surface. In fact, the surface has often edges that can be both asperities or depressions, namely ridges and valleys.

The code quantifies the non-planarity by means of principal curvature values associated to the DSM/DTM vertices, calculated implementing the method proposed by Chen and Schmitt (1992) and extended by Dong and Wang (2005). One can express the definitions of a ridge and a valley in terms of principal curvature values: a ridge is an edge formed by vertices which correspond to positive values of maximum principal curvature and which represent local maxima respect to the adjacent vertices; similarly, a valley is an edge formed by vertices which correspond to negative values of minimum principal curvature and which represent, in absolute value, local maxima respect to the adjacent vertices.

Therefore the user is asked for two thresholds on principal curvature: the first one $\left(\mathrm{T}_{\max }\right)$ on maximum principal curvature, to detect points belonging to significant convex edges, and the second one $\left(\mathrm{T}_{\min }\right)$ on minimum principal curvature, to detect points belonging to significant concave edges. Higher absolute values of $\mathrm{T}_{\max }$ and $\mathrm{T}_{\min }$ correspond to smaller numbers of accepted vertices, namely thinner bands of points along the edges (Fig. 2; Table 1). 
DTM resolution has a direct influence on results accuracy and completeness: in fact the sampling step to collect points on the surveyed object, and consequently the amplitude of the triangles of the DTM, influence the quality of the approximation of the real surface. In addition, the decrease of the resolution has an effect of "smoothing" and deterioration of the edges of the surface, which reduces the range of principal curvatures, and also depending on the triangulation, disrupts or alters the continuity of the edges. Thus the decrease of the resolution will decrease both the accuracy and completeness of the extracted edges from the real edges.

On the significant vertices of the DTM, identified by the thresholds, a series of processing (Umili, 2012) are made (connection, thickening, refining, segmentation, ..), which finally give the geometrical description of the edges (ordered list of vertices, parameters of interpolating line, length).

Figure 2. Comparison between accepted points using different thresholds pairs: (a) $\mathrm{T}_{\max }=0.0013$ and $\mathrm{T}_{\min }=-0.0008$ (b) $\mathrm{T}_{\max }=0.0009$ and $\mathrm{T}_{\min }=-0.0006$

\section{Table 1. Thresholds on curvature values assumed during CurvaTool processing}

After that, edges are automatically segmented by means of the RANSAC (Random Sample Consensus) algorithm (Fischler and Bolles,1981): for each edge the lines that better interpolate it are obtained and used to split the path according to their different directions (Fig. 3). This procedure allows one to create a database suitable to the following operations of cluster analysis, in which each segments has its own interpolating line; in fact, without the segmentation, edges would be represented by polylines, probably connecting different lineaments, whose mean directions could be very different from those gathered from literature data and in situ studies.

Figure 3. Edge segmentation with RANSAC algorithm; example of an edge split into 4 parts, each approximated by a segment

\subsection{Filter for statistical data treatment}

Post-processing operations on CurvaTool output are required in order to obtain only segments representing items of interest among all the reconstructed edges: therefore a specific algorithm, called Filter in the following, has been created to perform these operations. The user is asked for the orientations of the expected clusters of lineaments, expressed, for each cluster, by an angle respect to the North and the relative standard deviation. Filter code operates the classification of the dataset attributing each edge to the correspondent input cluster. Non-classified edges are recorded as "others". 


\section{The test area: the Monferrato geological domain}

The geological succession of the Monferrato is divided in a lower part of strongly deformed Apennine calcareous flysch (late Cretaceous to middle Eocene age) and an upper terrigenous succession (middle Eocene - Pliocene) resting unconformably on the previous one (Clari et al, 1995). In particular, the sedimentary sequence is mainly composed of marls, arenites, siltstone (with locally interbedded sandstone), evaporates, mudrocks and sandstones. The stratigraphic succession is characterized by lateral thickness variations and by the occurrence of local unconformities; it is poorly folded, but highly tilted and deformed in reason of a continuous uplift (also recent) which caused a structural control during geomorphological evolution. Steep slopes, well-organized drainage network, fractures and faults are the evident consequences of that interaction.

Tectonic boundaries divide Monferrato geological domain in tectonostratigraphic units which are characterized by distinctive sedimentary evolution, stratigrafical sequence, geometries and amount of deformation.

In particular, two main subdomains should be recognised (Fig. 4): the Western Monferrato, consisting of minor tectonostratigraphic fault-bounded units, and the Eastern Monferrato, consisting of an Eocene-Pliocene discontinuous succession interpreted as a single tectono-stratigraphic unit, separated by the Castel Verrua Fault Zone (CVFZ). The CVFZ is a NNWSSE trending fault of the Pliocene age which extends from the Po plain to the southern boundary of the Monferrato (Piana, 2000). The Eastern Monferrato (Fig. 5) has been interpreted as a single tectonostratigraphic unit whereas the Western Monferrato consists of minor tectonostratigraphic fault-bounded units controlled by pre-Langhian transpressive tectonies. To the W, the western Monferrato is separated to the Torino Hill by the NNW striking Rio Freddo Fault Zone which represents the surface evidence of the junction between an alpine related geological domain (Torino Hill area) and an Apennine related geological one (Monferrato area) (Piana and Polino, 1995). The contact between the Monferrato succession and the Messinian -Pliocene deposits (consisting of marls, evaporates, mudrocks, silty-clay and sands that lie on the south area of the Monferrato) is underlined by a straight line, called the "Monferrato Southern Fault System", that suggests a possible subvertical contact corresponding to an ENE-WSW fault system.

Despite the structural complexity and the presence of many deformation zones, four main systems of faults have been recognised in Monferrato (Piana, 2000; Dela Pierre et al, 2003). They are oriented NW-SE, NE-SW, E-W and N-S respectively.

Figure 4. Structural sketch map of northwestern Alps and westernmost part of northern Apennines. Different domains of Tertiary Piemonte Basin are here shown in detail. AM, Alto Monferrato domain; BG, Borbera-Grue domain; WM, 
Western Monferrato domain; TH, Torino Hill domain; IL, Insubric line; SVZ, Sestri Voltaggio Zone; LVV, Villalvernia-Varzi line; PTF, Padan Thrust Front (Source Piana, 2000)

Figure 5. Structural sketch map of Torino Hill and Monferrato domains (Source Piana, 2000)

\section{Results}

The DTM of Monferrato was processed by means of CurvaTool software, obtaining 883 lineaments (Fig. 6).

Figure 6. Map of lineaments of Monferrato DTM extracted by CurvaTool, distinguished into ridges (red) and ravines (blue)

The azimuthal frequency distribution of lineaments are shown in figure (Fig. 7a): a wider distribution range is evident and four main lineaments systems can be recognized, oriented respectively E-W, NW-SE, N-S and NE-SW. The NWSE lineaments show a wide distribution in different classes, particularly in the range between $300^{\circ}$ and $330^{\circ}$ respect to North (expressed by the notation N300-330), with the higher cumulative frequency in respect to the other systems. The NE-SW system is less frequent, but it is also marked by a distribution in different classes with a maximum in the N4060 azimuthal classes. The N-S lineaments show a very high frequency just in the N0-10 direction, as well as the E-W lineaments are mainly concentrated with a medium frequency in the N270-280 direction.

Extracted lineaments have also been characterized in terms of cumulative length and length classes. In order to compare CurvaTool data with literature data and to validate the application of the code, the same classes of length proposed by Morelli and Piana (2006) have been applied.

According to the cumulative length diagram, in Monferrato the NW-SE, E-W and N-S lineaments preset a similar cumulative length, which is higher than the NE-SW lineaments one (Fig. 7b).

Figure 7. (a) Azimuthal frequency and (b) cumulative length diagrams for CurvaTool lineaments of Monferrato. Frequency values have been recalculated as percentages

With regard to the length classes distributions, CurvaTool data shows long and intermediate lineaments on the NW-SE direction and mainly short and intermediate length on the N-S and NE-SW direction. The E-W lineaments show a similar distribution in the three length classes (Fig. 8). 

.

Figure 8. Azimuthal frequency of lineaments divided in classes of length

Due to the abundance of lineaments, in order to simplify results processing and graphical identification of the different systems, Filter (see par. 2.2) was applied; coherently with azimuthal frequency of the lineaments, orientation values in Table 2 have been assumed as input data.

\section{Table 2. Orientation of clusters used as input for Filter}

After the application of Filter, lineaments belonging to the different systems are automatically represented in distinct colors (Fig. 9) and the image representing CurvaTool results can be easily interpreted.

As observed, the NW-SE striking system (L1) shows the greatest frequency and length with long or intermediate lineaments uniformly distributed in the area. The NE-SW system (L2) is less frequent and shows shorter lineaments mainly distributed in the centre and in the north-western part of the studied area; in particular, the longest lineaments of this system are concentrated in the north-western part of the map. The E-W striking system (L3) shows a lower frequency and it has been mainly identified in the centre and north-western sector of the map with both short, intermediate and long lineaments. The N-S striking system (L4) is present in the whole area with short and intermediate length and it is particularly frequent in the southern area of the map.

Figure 9. Image of Monferrato DTM with lineaments extracted by CurvaTool and processed with Filter. Four sets are visible: L1 (fuchsia), L2 (green), L3 (blue) and L4 (yellow)

According to orientation, frequency, length and spatial distribution of the lineaments, different sectors with distinct structural styles should be recognizable on the map (Fig. 10).

From the centre to the north-western part of the map (sector B), all lineament systems were recognized. The NW-SE (L1) and the NE-SW (L2) striking systems are predominant; in particular, sector B is the only one within the NE-SW striking system is particularly distributed and shows the longest lineaments (specially on N30-50 direction). L1 consists of intermediate-length lineaments on the N310-350 direction. L3 (E-W) is well represented with long and intermediatelength lineaments on the N270-280 direction, while L4 (N-S) lineaments are less frequent and show short to intermediate lengths.

The south-eastern part of the map (sector A) is characterized by long L1 (N310-330) and L3 lineaments (particularly distributed in the north and north-western part of this sector). L2 is poorly represented both in frequency and length, 
whereas L4 has a wider distribution than in sector B, particularly in the center, with intermediate and long lineaments on N0-10 direction.

The south western part of the image (sector C) is the less deformed area. It is characterized by the lowest frequency of lineaments: L1 is still present with a few intermediate-length lineaments (N310-340), L2 and L3 are poorly represented and are concentrated principally in the northern and north-eastern border of the sector, respectively. Unlike the other sectors, L4 is clearly represented and regularly distributed in the whole sector with intermediate to long lineaments on N0-10 direction.

The north-eastern area (sector D) is partially represented and it is too small to be statistically significant, nevertheless a predominance of L1, with N310-350 intermediate lineaments, and a few intermediate L4 lineaments are evident.

Figure 10. Four sectors (A, B, C, D) with distinct structural styles identified according to orientation, frequency, length and spatial distribution of lineaments

\section{Discussion}

Geological structures manually extracted through photointerpretation, remote sensing (Morelli and Piana, 2006) or derived by geological maps and field survey (Dela Pierre et al., 2003; Piana and Polino, 1995; Piana, 2000) were compared with the semi-automatic outputs of CurvaTool with regard to orientation, frequency, spatial distribution and length of the lineaments.

The four lineament systems identified by the CurvaTool processing are coherently both with literature and field data (Piana, 2000; De la Pierre et al., 2003). In particular they show a similar frequency distribution to the faults measured on the field in the whole Monferrato (Fig. 11) and to the lineaments extracted by Morelli and Piana (2006) using Spot and SAR image analysis.

Figure 11. Rose diagrams of azimuthal frequency of (a) CurvaTool lineaments, (b) faults measured in field in whole Monferrato (Dela Pierre et al, 2003)

In regards to satellites image analysis, Morelli and Piana (2006) have observed that the aggregation of lineaments detected from both SAR and Spot image are complementary, because Spot does not work well along the N330 direction and SAR along the E-W, due to the different illumination direction. 
1 CurvaTool data show a good correspondence with the results of the remote sensed analysis and furnish a synthesis of the Spot and SAR data: in particular, it evidences the presence of a N-S striking system, as for the SAR data, but also underlines the E-W System, as for the Spot data.

As mentioned in the previous paragraph, CurvaTool data were analyzed using the same classes of length used in the same area by Morelli and Piana (2006), in order to compare data and validate CurvaTool processing. Number of lineaments, azimuthal frequency and cumulative length were calculate for each class of length. As reported in Table $3,4,5$ and 6, very similar percentages were obtain concerning azimuthal frequency of the lineaments in the classes of length with differences ranging from 0 to about $4 \%$.

Table 3. Azimuthal frequency, cumulative lengths and azimuthal frequency divided into classes of lengths, following criteria used by Morelli and Piana (2006) for Spot HRV data, of lineaments automatically extracted by CurvaTool on Monferrato DTM

Table 4. Azimuthal frequency, cumulative lengths and azimuthal frequency divided into classes of lengths, following criteria used by Morelli and Piana (2006) for ERS-2 SAR data, of lineaments automatically extracted by CurvaTool on Monferrato DTM

Table 5. Differences between results in Table 3 and those obtained by Morelli and Piana (2006) with Spot HRV data

Table 6. Differences between results in Table 4 and those obtained by Morelli and Piana (2006) with ERS-2 SAR data

The number of lineaments obtained with CurvaTool for each azimuthal direction shows a good correspondence with the Spot data, with the only exception of the NW-SE direction, where a higher number of CurvaTool lineaments are present. Major differences are evident between the number of lineaments detected by CurvaTool and those of the Spot data, except for the E-W direction.

About spatial distribution of the lineaments, the sub-domains derived by the image of CurvaTool results (Fig. 10) show a great correspondence with the structural domains indicated by Piana and Polino (1995) and the sub-domains recognized (A, B and C) by Morelli and Piana (2006) (Fig. 12).

Figure 12. Image of Monferrato DTM with lineaments and sub-domains extracted by (a) CurvaTool and (B) Spot HVR data (Morelli and Piana, 2006) 
These sectors are characterized by distinct arrangements of different-length lineaments and spatial distribution. It is possible to remark that the lineament geometries are very similar to those of the geological structures at different scales. Both CurvaTool analysis and remote sensed processing (Morelli and Piana, 2006) have identified different sectors (A, B and C) with distinct arrangements of length and orientation of lineaments. In particular, the sectors A and B shown major deformation with the prevalence of the NW-SE lineaments in the sector A and NE-SW lineaments in the sector B.

\section{Conclusions}

Through this work, the authors propose and test the use of an innovative method for the extraction of geological features using a semi-automatic approach, based on the code CurvaTool. This code was originally developed to operate on DSM (Digital Surface Model) of natural rock mass outcrops. In this work, the code has been applied to DTMs of large portion of territory in order to semi-automatically detect edges which represent potential geological lineaments. In order to validate the results obtained by the software with the data in literature, an area geologically known (Monferrato domain) has been chosen.

With regard to orientation, frequency, spatial distribution and length of the lineaments, the semi-automatic outputs of CurvaTool were compared to geological structures that were manually extracted through photointerpretation, remote sensing and field surveys known from literature.

A good correspondence between literature data and CurvaTool results was found in regard to geometry and distribution of the lineaments. Four lineament systems, NW-SE (L1), NE-SW (L2), E-W (L3) and N-S (L4) directions, have been identified by CurvaTool processing. These lineaments define different sectors with distinct structural arrangement, coherently with literature and field data.

In particular CurvaTool data show a similar frequency distribution to the lineaments extracted by Morelli and Piana (2006) analyzing Spot and SAR images and furnishing a synthesis of Spot and SAR data with a compensation of the specific anomalies due to the orbit of the satellites.

To sum up, the first results of software application are good: the outputs of the code CurvaTool, applied to DTMs in order to detect potential geological lineaments, show a good correspondence with literature data. At any rate, software should be improved in order to refine the correspondence between lineaments and geological structures. It has been observed that some of the lineaments reported in geological maps and literature correspond in orientation and position to CurvaTool lineaments. In order to verify that correspondence, subsequent analyses and processing have to be accomplished. This theme will be extended and evaluated in future work. 


\section{References}

Carrapa, B., Garcia-Castellanos, D., 2005. Western Alpine back-thrusting as subsidence mechanism in the Tertiary Piedmont Basin (Western Po Plain, NW Italy). Tectonophysics 406(3-4), 197-212

Carrapa, B., Bertotti, G., Krijgsman, W., 2003. Subsidence, stress regime and rotation(s) of a tectonically active sedimentary basin within the western Alpine Orogen: The Tertiary Piedmont Basin (Alpine domain, NW Italy). In: McCann, T., Saintot, A. (Eds.), Tracing Tectonic Deformation Using the Sedimentary Record, Special Publication, Geological Society of London, vol. 208, pp. 205227.

Casas, A.M., Cortés, A.L., Maestro, A., Soriano, M.A., Riaguas, A., Bernal, J., 2000. LINDENS: A program for lineament length and density analysis. Computers \& Geosciences 26, 1011-1022.

Castellarin, A., 2001. Alps-Apennine and Po Plain-frontal Apennines relations. In: Anatomy of an Orogen, The Apennines and Adjacent Mediterranean Basins. Vai, F., Martini, I. Peter (Eds.), pp. 177-195.

Chen, X., Schmitt, F., 1992. Intrinsic Surface Properties from Surface Triangulation. Proceedings of the European Conference on Computer Vision, pp. 739-743.

Clari, P., Dela Pierre, F., Novaretti, A., Timpanelli, M., 1995. Late Oligocene-Miocene sedimentary evolution of the critical Alps/Apennines junction: the Monferrato area, northwestern Italy. Terra Nova 7(2), 144-152.

Cracknell, M.J., Roach, M., Green, D., Lucieer, A., 2013. Estimating Bedding Orientation From High-Resolution Digital Elevation Models. IEEE Transactions On Geoscience And Remote Sensing 51(5), 2949 - 2959.

D’Atri, A., Dela Pierre, F., Gelati, R., Gnaccolini, M., Piana, F., Polino, R., 2002. Il Bacino Terziario Piemontese. In: Polino, R.

(Ed.), Il Sistema Alpino-Appenninico nel Cenozoico. $81^{\circ}$ Riunione Estiva della Societa` Geologica Italiana: Guida alle escursioni del 6-9 Settembre 2002, pp. 110 - 115 [in Italian].

Dela Pierre, F., Fioraso, G., Piana, F., Boano, P., 2003. Foglio 157 ‘Trino’ della Carta Geologica d'Italia alla scala 1 : 50,000. APAT, Dipartimento Difesa del Suolo, Roma.

Dong, C., Wang, G., 2005. Curvatures estimation on triangular mesh. Journal of Zhejiang University SCIENCE 6A(Suppl I), pp. 128-136. 
Ekneligoda, T.C., Henkel, H., 2006. The spacing calculator software - A Visual Basic program to calculate spatial properties of lineaments. Computers \& Geosciences 32, 542-553.

Fischler, M., Bolles, R., 1981. Random sample consensus: a paradigm for model fitting with application to image analysis and automated cartography. Communications of the Association for Computing Machinery, 24(6): 381-395.

Gelati, R., Gnaccolini, M., 1998. Synsedimentary tectonics and sedimentation in the Tertiary Piedmont Basin, Northwestern Italy. Rivista Italiana di Paleontologia e Stratigrafia, 104(2), 193-214.

Gueguen, E., Doglioni, C., Fernandez, M., 1998. On the post-25 Ma geodynamic evolution of the western Mediterranean. Tectonophysics 298(1-3), 259-269.

Hashim, M, Ahmad, S, Johari, M.A.M., Pour, A.B., 2013. Automatic lineament extraction in a heavily vegetated region using Landsat Enhanced Thematic Mapper (ETM+) imagery. Advances in Space Research 51(5), 874-890.

Hoogerduijn Strating, E.H., Van Wamel, W.A., Vissers, R.L.M., 1991. Some constraints on the kinematics of the Tertiary Piemonte Basin (northwest Italy). Tectonophysics 198(1), 47- 51.

Jordan, G., Schott, B., 2005. Application of wavelet analysis to the study of spatial pattern of morphotectonic lineaments in digital terrain models. A case study. Remote Sensing of Environment 94(1), 31-38.

Jordan, G., Meijninger, B.M.L., Van Hinsbergen, D.J.J., Meulenkamp, J.E., Van Dijk, P.M., 2005. Extraction of morphotectonic features from DEMs: Development and applications for study areas in Hungary and NW Greece. International Journal of Applied Earth Observation and Geoinformation 7(3), 163-182.

Lim, C.S., Ibrahim, K., Tjia, H.D., 2001. Radiometric and Geometric information content of TiungSat-1 MSEIS data. In: TiungSAT1: From Inception to Inauguration, pp. 169-184.

Masoud, A., Koike, K., 2011. Auto-detection and integration of tectonically significant lineaments from SRTM DEM and remotelysensed geophysical data. ISPRS Journal of Photogrammetry and Remote Sensing 66, 818-832.

Morelli, M., Piana, F., 2006. Comparison between remote sensed lineaments and geological structures in intensively cultivated hills (Monferrato and Langhe domains, NW Italy). International Journal of Remote Sensing 27(20), 4471-4493. 
Piana, F., 2000. Structural setting of Western Monferrato (Alps-Apennines Junction zone, NW Italy). Tectonics 19(5), 943-960.

Piana, F., Polino, R., 1995. Tertiary structural relationships between Alps and Apennines: the critical Torino Hill and Monferrato area, northwestern Italy. Terra Nova 7(2), 138-143.

Roure, F., Polino, R., Nicolich, R., 1990. Early Neogene deformation beneath the Po Plain: constraints on the post-collisional Alpine evolution. Memoires de la Société Géologique de France 156, 309-322.

Saadi, N.M., Abdel Zaher, M., El-Baz, F., Watanabe, K., 2011. Integrated remote sensing data utilization for investigating structural and tectonic history of the Ghadames Basin, Libya. International Journal of Applied Earth Observation and Geoinformation 13(5), $778-791$.

Schmid, S.M., Kissling, E., 2000. The arc of the Western Alps in the light of geophysical data on deep crustal structure. Tectonics $19(1), 62-85$.

Umili, G., Ferrero, A.M., Einstein, H.H., 2013. A new method for automatic discontinuity traces sampling on rock mass 3D model. Computers \& Geosciences 51, 182-192.

Umili, G., 2012. Automatic Reconstruction of Breaklines in Digital Surface Models applied to Geotechnics and Architecture. In: Ricerche di Geomatica 2012. p. 79-88, Bologna: Gabriele Bitelli, ISBN: 978-88-905917-1-6

Wladis, D., 1999. Automatic Lineament Detection Using Digital Elevation Models with Second Derivative Filters. Photogrammetric Engineering \& Remote Sensing 65(4), 453-458. 
Click here to download high resolution image

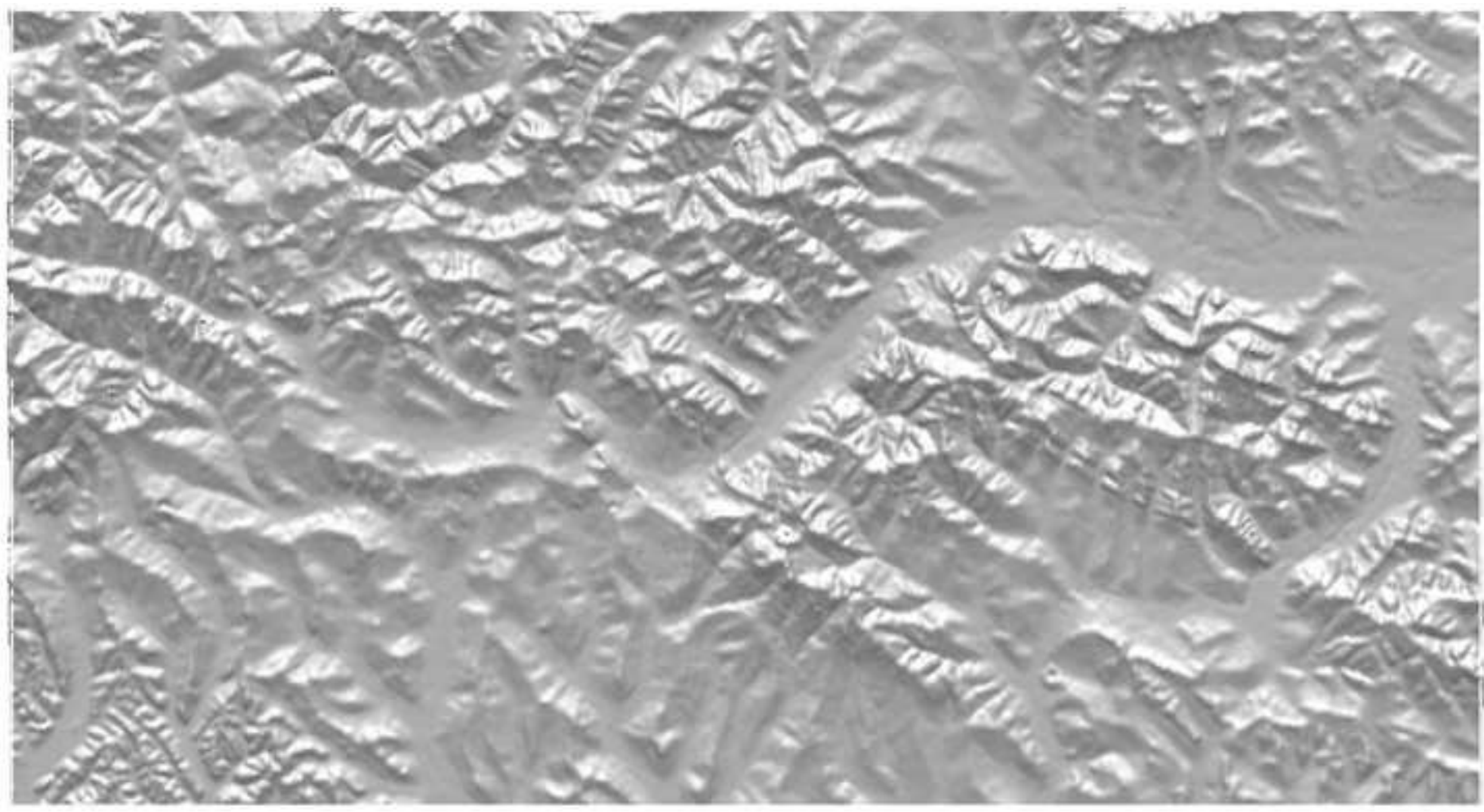


Click here to download high resolution image
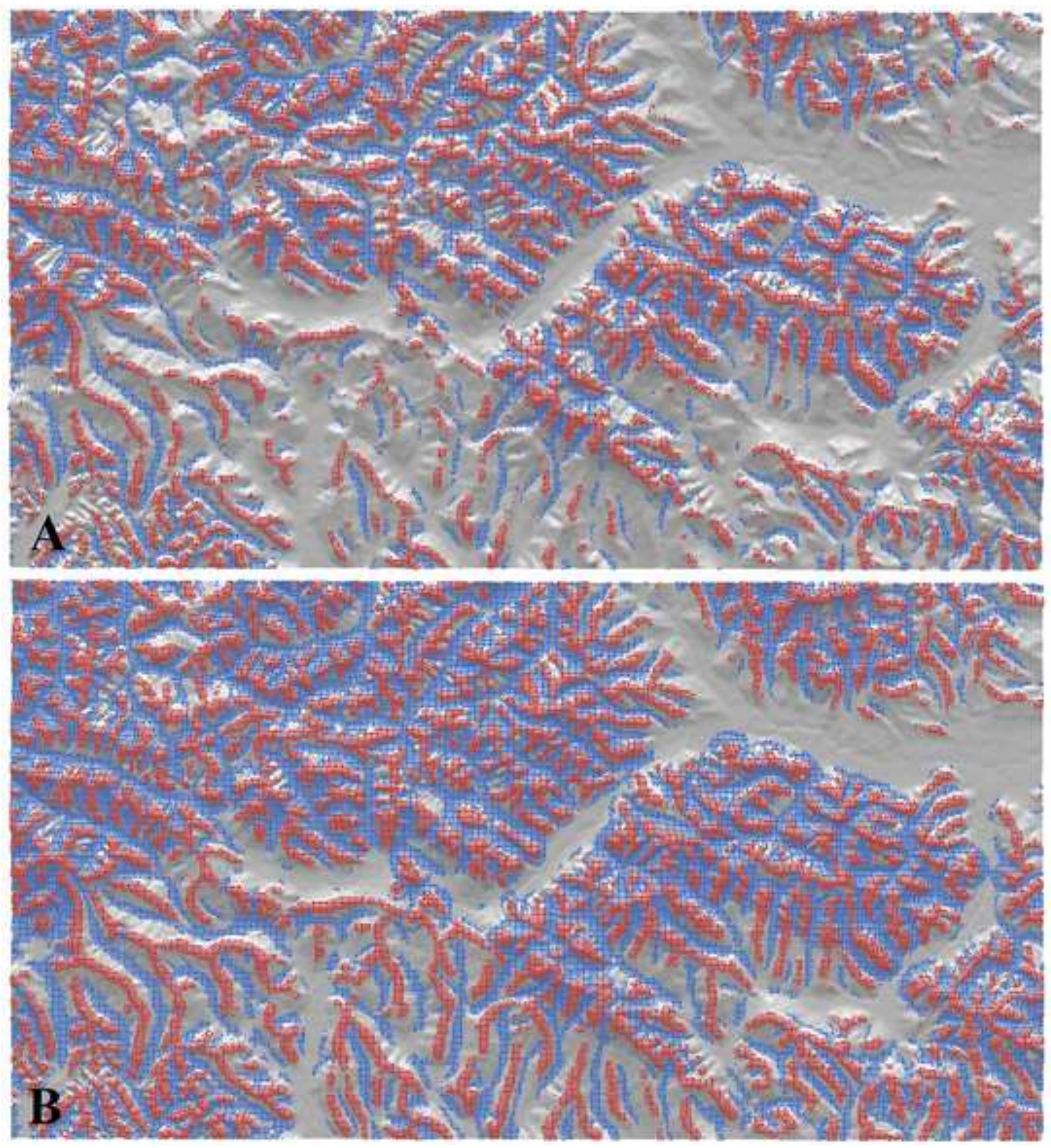
Click here to download high resolution image

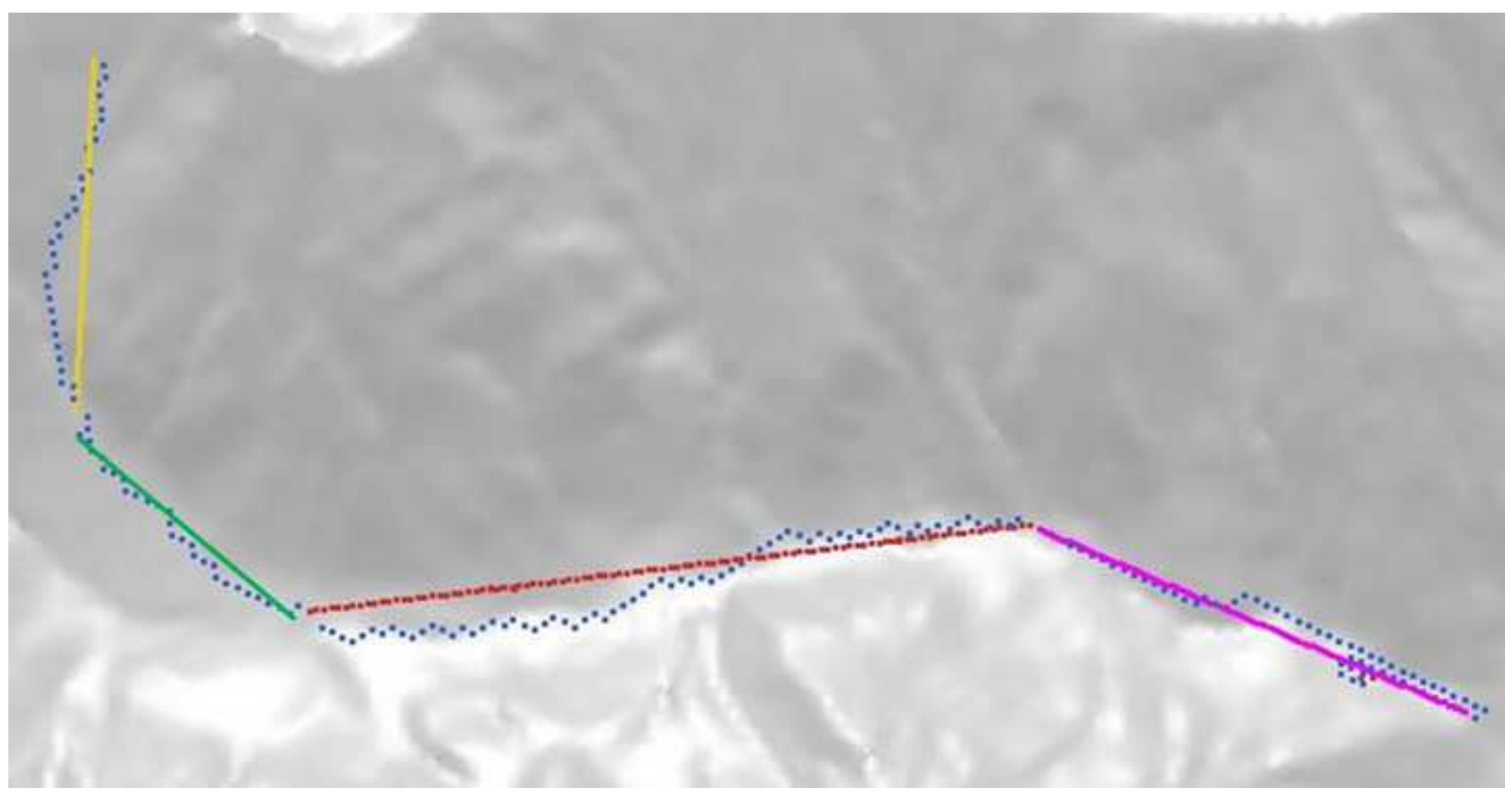


Click here to download high resolution image

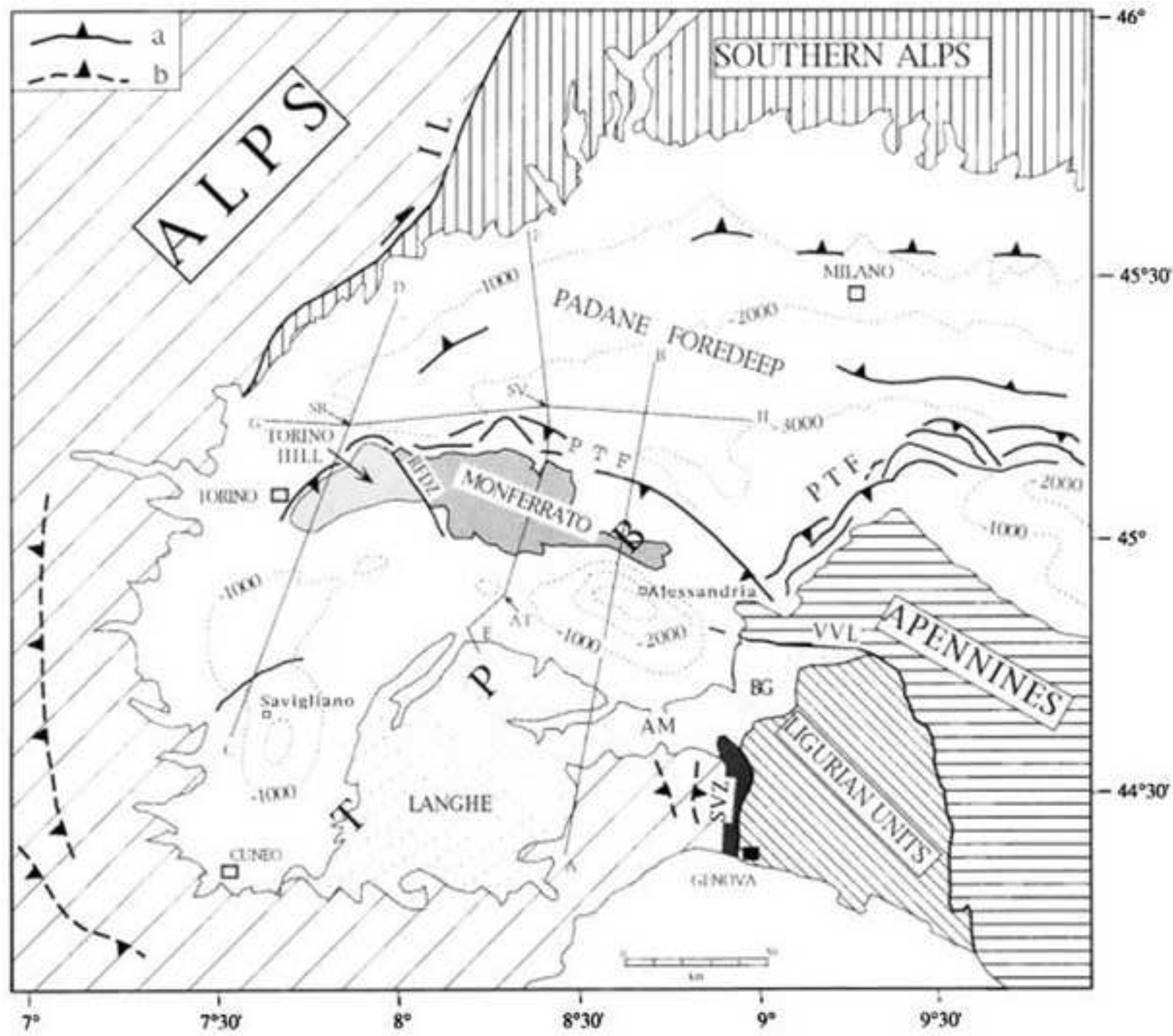




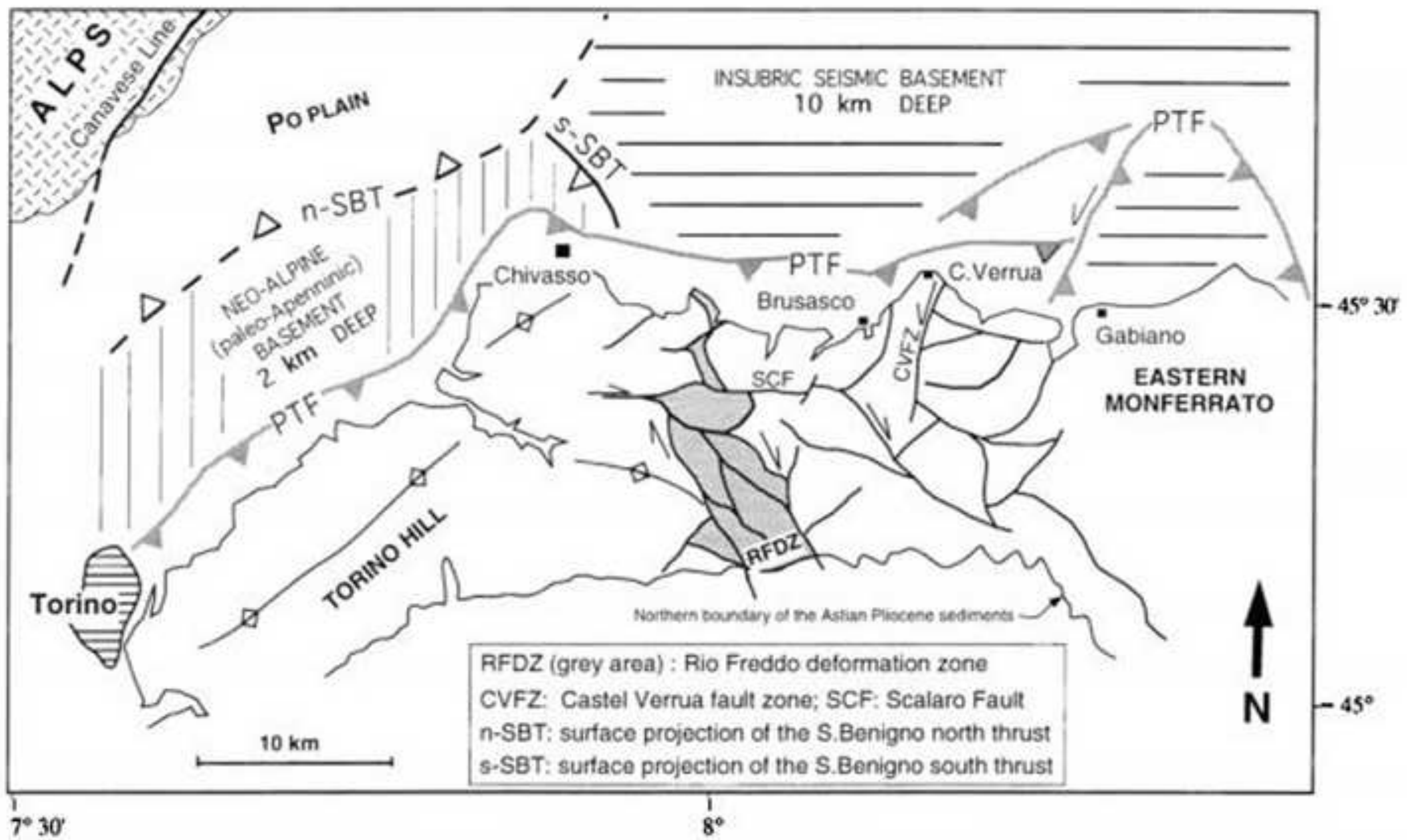



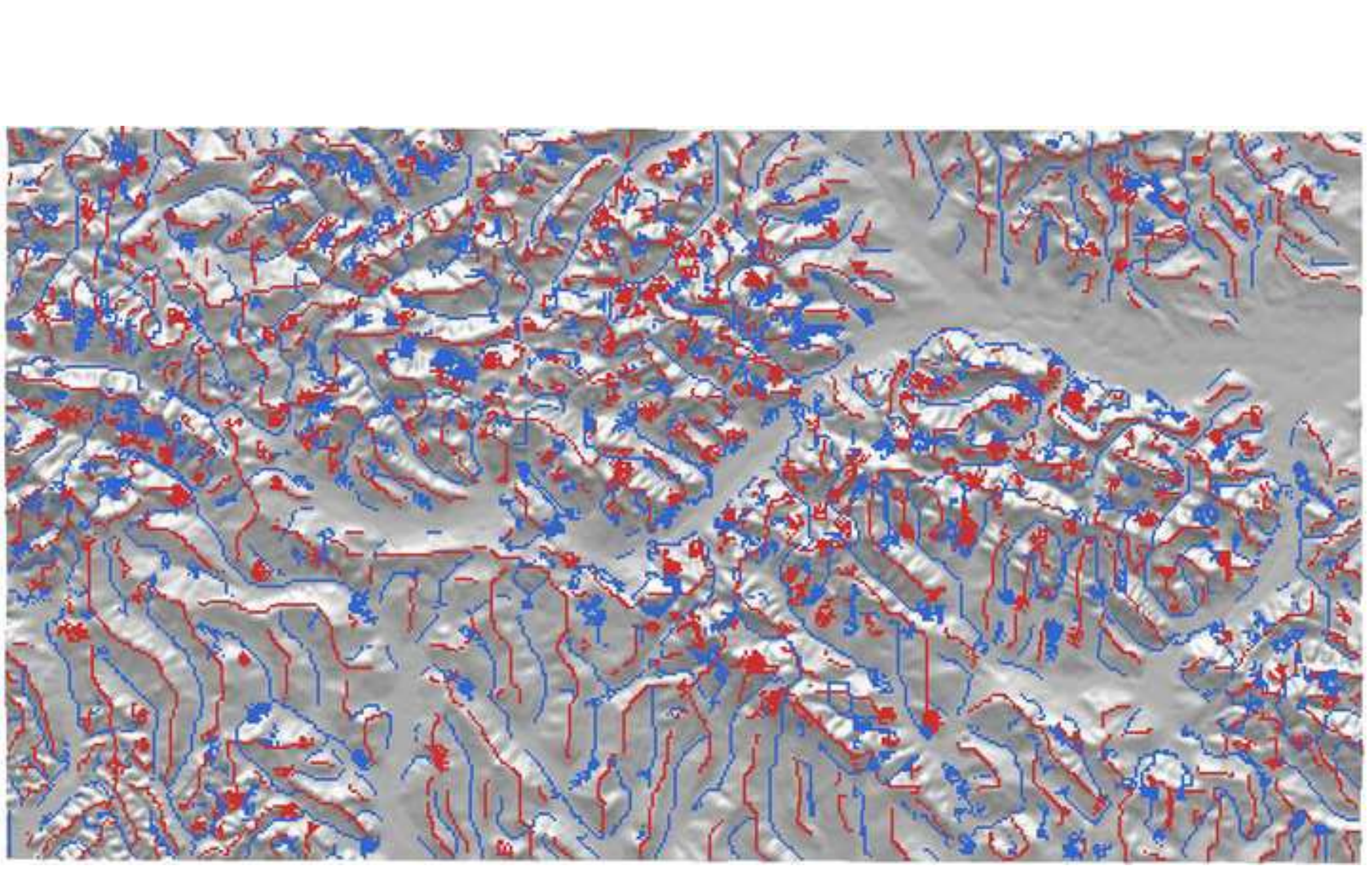

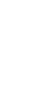

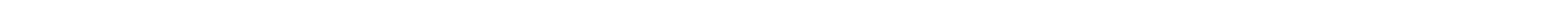

to download high resolution image

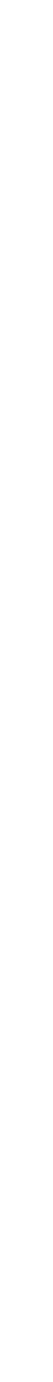



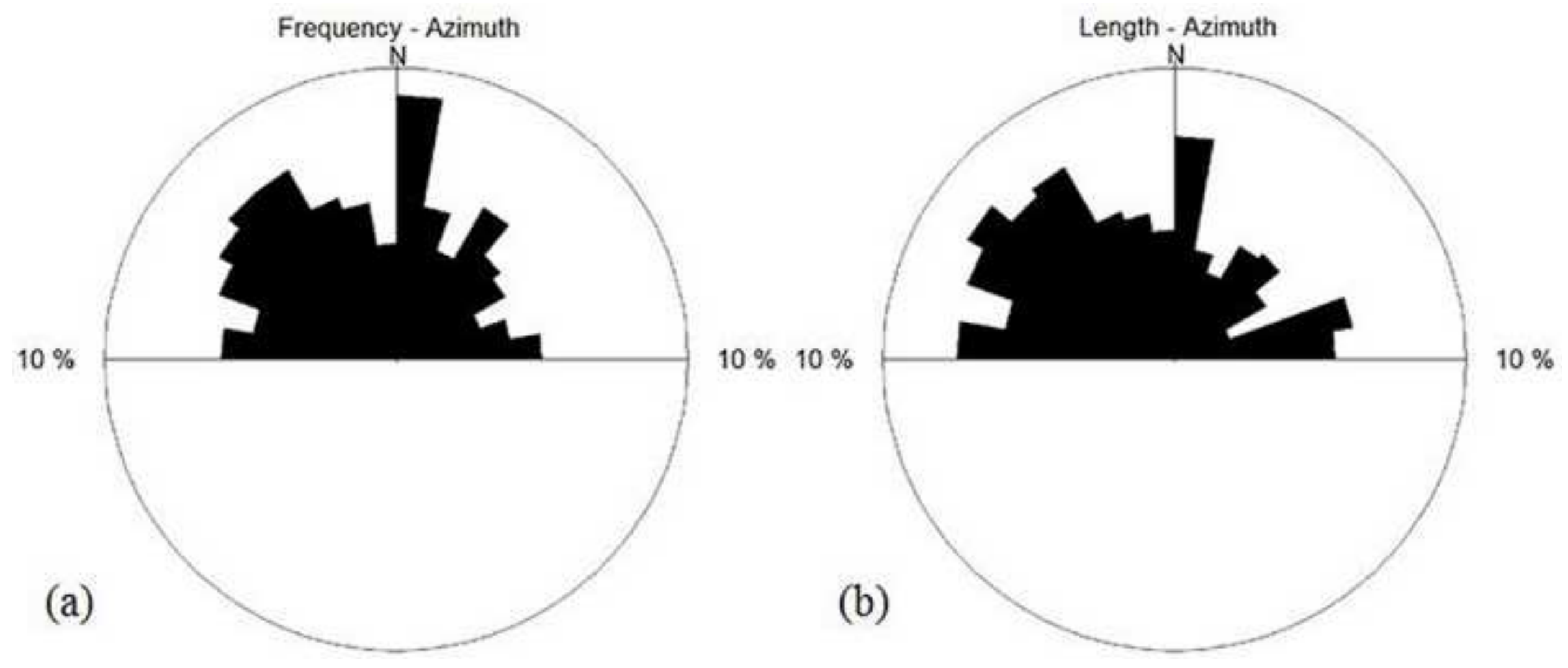


\section{Figure 8}

Click here to download high resolution image

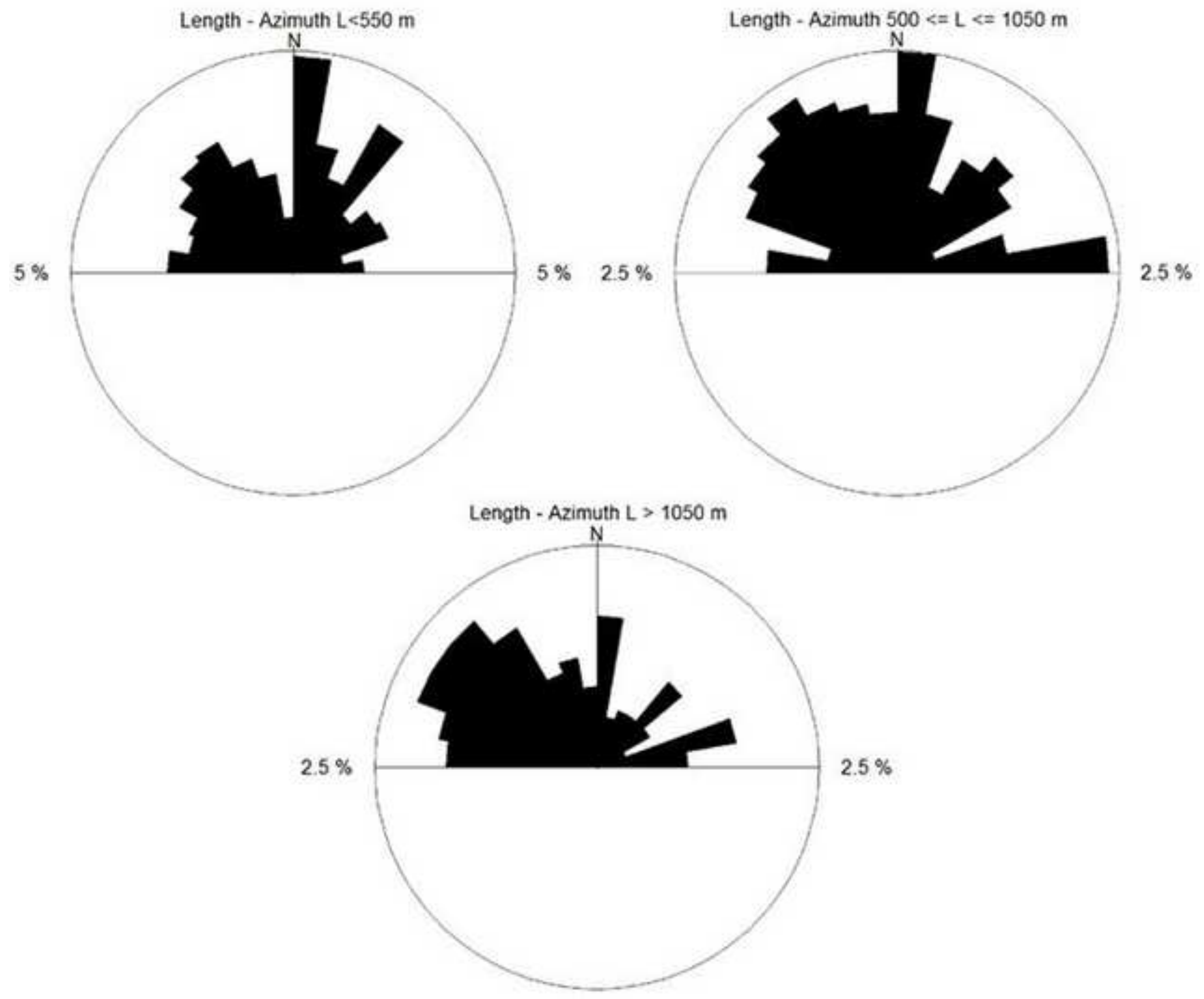


Click here to download high resolution image

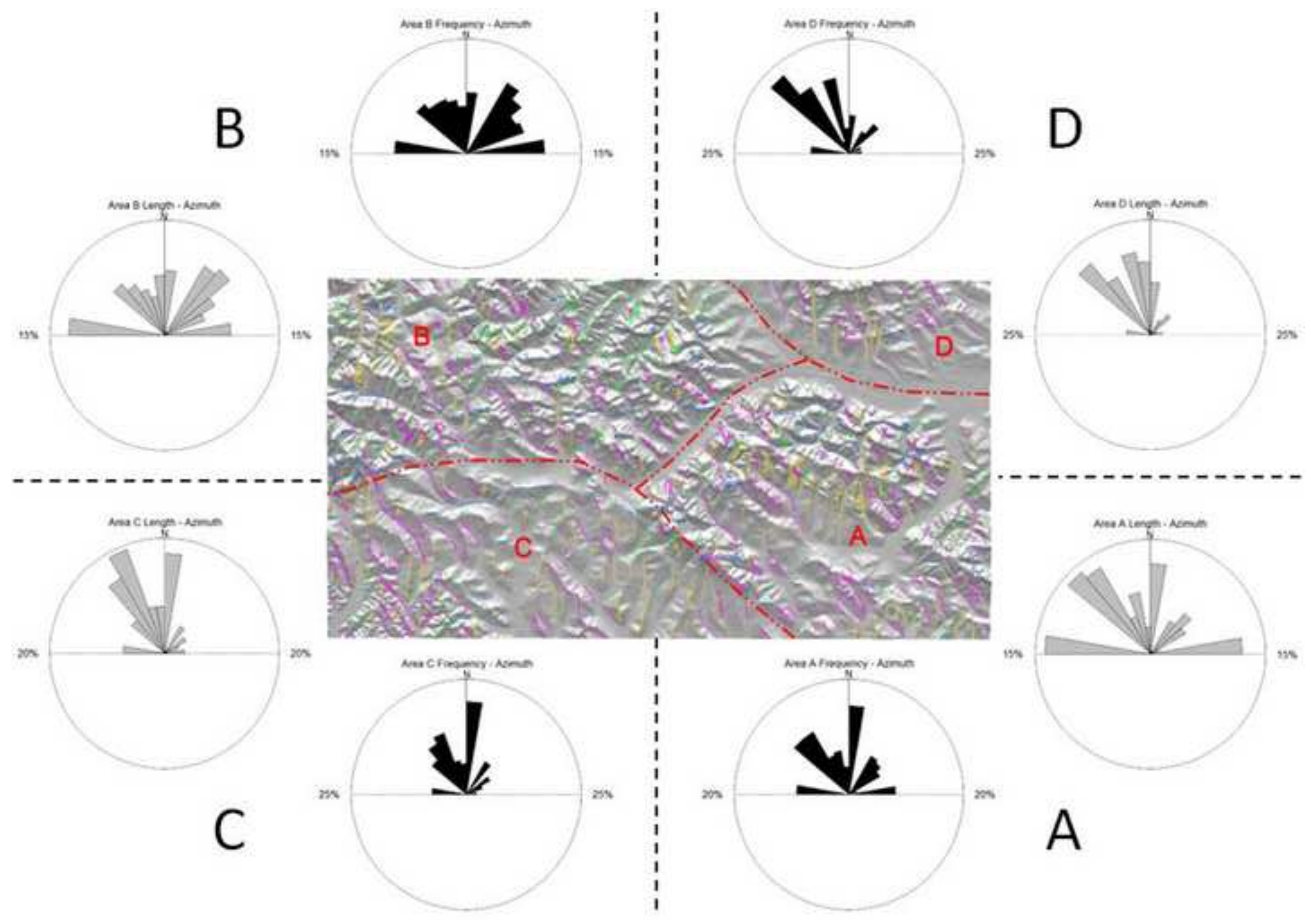



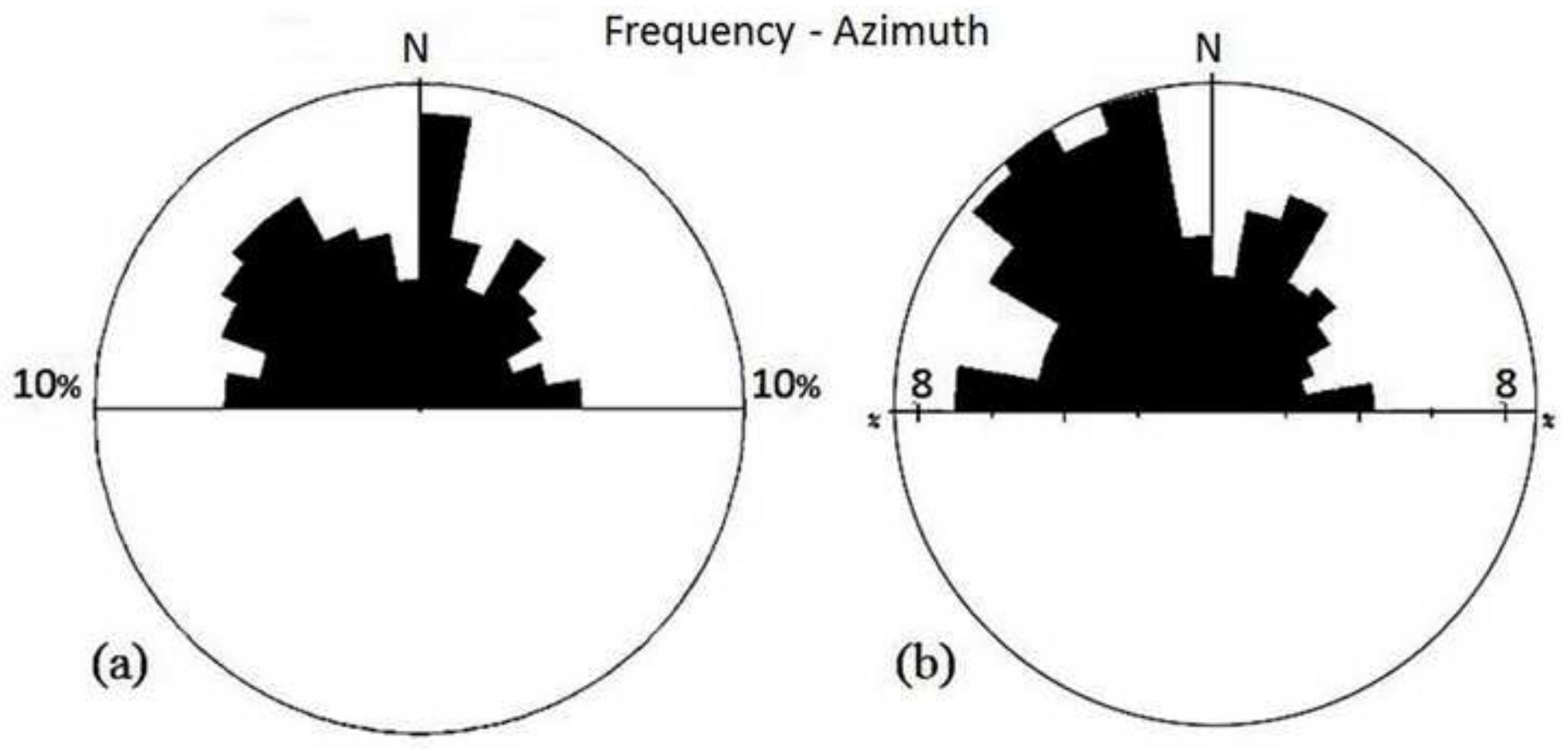
Click here to download high resolution image

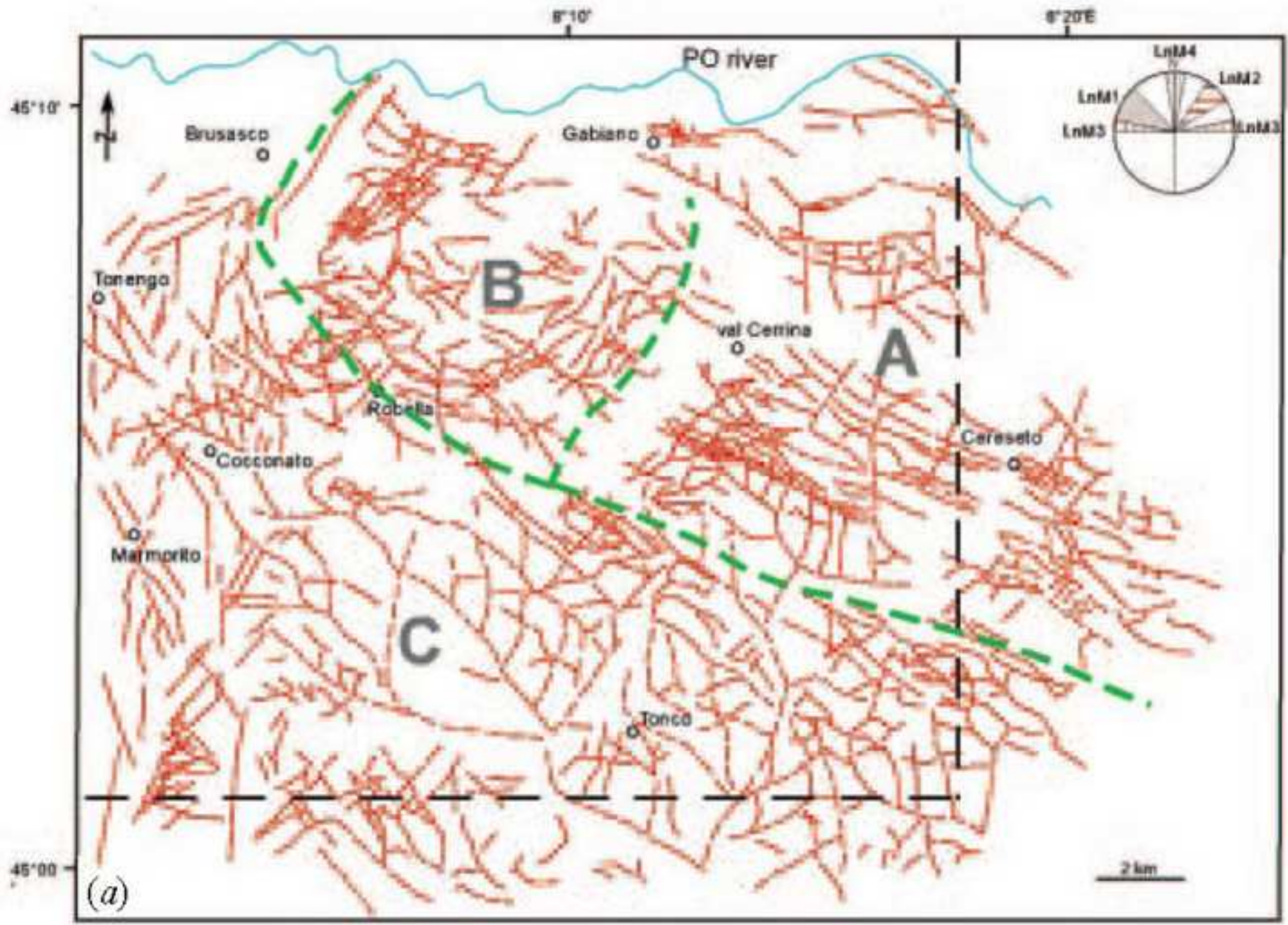


Table 1

Table 1. Thresholds on curvature values assumed during CurvaTool processing

\begin{tabular}{cc}
\hline Tmax & Tmin \\
{$[-]$} & {$[-]$} \\
\hline 0.0013 & -0.0008
\end{tabular}

$+$ 
Table 2

Table 2. Orientation of clusters used as input for Filter

\begin{tabular}{ccc}
\hline cluster & $\begin{array}{c}\text { Azimuthal direction } \\
\text { Standard deviation } \\
{\left[{ }^{\circ}\right]}\end{array}$ & $\begin{array}{c}\left.{ }^{\circ}\right] \\
\text { L1 }\end{array}$ \\
$\mathbf{L 2}$ & 330 & 20 \\
$\mathbf{L 3}$ & 50 & 20 \\
$\mathbf{L 4}$ & 90 & 10 \\
\hline
\end{tabular}


Table 3. Azimuthal frequency, cumulative lengths and azimuthal frequency divided into classes of lengths, following criteria used by Morelli and Piana (2006) for Spot HRV data, of lineaments automatically extracted by CurvaTool on Monferrato DTM.

\begin{tabular}{|c|c|c|c|c|c|c|c|}
\hline $\begin{array}{l}\text { Azimuthal } \\
\text { directions }\end{array}$ & $\begin{array}{c}\mathbf{n}^{\circ} \\
\text { lineaments }\end{array}$ & $\begin{array}{c}\% \mathbf{f} \\
\text { azimuthal }\end{array}$ & $\begin{array}{c}\% \mathbf{f} \\
\mathbf{L}<550 \\
\mathbf{m}\end{array}$ & $\begin{array}{c}\% \text { f } \\
550 \leq \mathrm{L} \leq 1050 \\
\mathrm{~m}\end{array}$ & $\begin{array}{c}\% \mathrm{f} \\
\mathrm{L}>1050 \\
\mathrm{~m}\end{array}$ & $\begin{array}{l}\Sigma \mathbf{L} \\
(\mathbf{m})\end{array}$ & $\begin{array}{r}\% \\
\Sigma \mathbf{L}\end{array}$ \\
\hline $270-279.99$ & 53 & 6.00 & 2.83 & 1.47 & 1.70 & 54317 & 7.47 \\
\hline $280-289.99$ & 44 & 4.98 & 2.38 & 0.79 & 1.81 & 42774 & 5.88 \\
\hline $290-299.99$ & 57 & 6.46 & 2.49 & 1.81 & 2.15 & 54959 & 7.56 \\
\hline 300-309.99 & 62 & 7.02 & 2.94 & 1.93 & 2.15 & 59402 & 8.17 \\
\hline $310-319.99$ & 66 & 7.47 & 3.28 & 2.04 & 2.15 & 53133 & 7.31 \\
\hline $320-329.99$ & 66 & 7.47 & 3.40 & 2.27 & 1.81 & 55257 & 7.60 \\
\hline $330-339.99$ & 52 & 5.89 & 2.72 & 2.04 & 1.13 & 39183 & 5.39 \\
\hline $340-349.99$ & 48 & 5.44 & 2.27 & 1.93 & 1.25 & 36855 & 5.07 \\
\hline $350-359.99$ & 35 & 3.96 & 1.25 & 1.81 & 0.91 & 32165 & 4.42 \\
\hline 0- 9.99 & 80 & 9.06 & 4.87 & 2.49 & 1.70 & 55618 & 7.65 \\
\hline $10-19.99$ & 47 & 5.32 & 2.94 & 1.81 & 0.57 & 27577 & 3.79 \\
\hline $20-29.99$ & 35 & 3.96 & 2.27 & 1.02 & 0.68 & 23127 & 3.18 \\
\hline $30-39.99$ & 53 & 6.00 & 3.85 & 1.47 & 0.68 & 32547 & 4.48 \\
\hline $40-49.99$ & 41 & 4.64 & 1.70 & 1.70 & 1.25 & 34087 & 4.69 \\
\hline $50-59.99$ & 38 & 4.30 & 2.15 & 1.47 & 0.68 & 26326 & 3.62 \\
\hline $60-69.99$ & 27 & 3.06 & 2.27 & 0.45 & 0.34 & 14656 & 2.02 \\
\hline $70-79.99$ & 35 & 3.96 & 1.13 & 1.25 & 1.59 & 45026 & 6.19 \\
\hline $80-90$ & 44 & 4.98 & 1.59 & 2.38 & 1.02 & 40142 & 5.52 \\
\hline Total & 883 & 100 & 46.32 & 30.12 & 23.56 & 727150 & 100 \\
\hline
\end{tabular}


Table 4. Azimuthal frequency, cumulative lengths and azimuthal frequency divided into classes of lengths, following criteria used by Morelli and Piana (2006) for ERS-2 SAR data, of lineaments automatically extracted by CurvaTool on Monferrato DTM.

\begin{tabular}{|c|c|c|c|c|c|c|c|}
\hline $\begin{array}{c}\text { Azimuthal } \\
\text { directions }\end{array}$ & $\begin{array}{c}\mathbf{n}^{\circ} \\
\text { lineaments }\end{array}$ & $\begin{array}{c}\% \mathrm{f} \\
\text { azimuthal }\end{array}$ & $\begin{array}{c}\% \mathbf{f} \\
\mathrm{L}<600 \\
\mathrm{~m}\end{array}$ & $\begin{array}{c}\% \mathrm{f} \\
600 \leq \mathrm{L} \leq 1050 \\
\mathrm{~m}\end{array}$ & $\begin{array}{c}\% \mathrm{f} \\
\mathrm{L}>1050 \\
\mathrm{~m}\end{array}$ & $\begin{array}{l}\text { SL } \\
\text { (m) }\end{array}$ & $\begin{array}{r}\% \\
\text { SL }\end{array}$ \\
\hline $270-279.99$ & 53 & 6.00 & 2.94 & 1.36 & 1.70 & 54317 & 7.47 \\
\hline $280-289.99$ & 44 & 4.98 & 2.72 & 0.45 & 1.81 & 42774 & 5.88 \\
\hline $290-299.99$ & 57 & 6.46 & 2.83 & 1.47 & 2.15 & 54959 & 7.56 \\
\hline $300-309.99$ & 62 & 7.02 & 3.28 & 1.59 & 2.15 & 59402 & 8.17 \\
\hline $310-319.99$ & 66 & 7.47 & 3.51 & 1.81 & 2.15 & 53133 & 7.31 \\
\hline $320-329.99$ & 66 & 7.47 & 3.96 & 1.70 & 1.81 & 55257 & 7.60 \\
\hline $330-339.99$ & 52 & 5.89 & 3.17 & 1.59 & 1.13 & 39183 & 5.39 \\
\hline $340-349.99$ & 48 & 5.44 & 2.49 & 1.70 & 1.25 & 36855 & 5.07 \\
\hline $350-359.99$ & 35 & 3.96 & 1.36 & 1.70 & 0.91 & 32165 & 4.42 \\
\hline $0-9.99$ & 80 & 9.06 & 5.32 & 2.04 & 1.70 & 55618 & 7.65 \\
\hline $10-19.99$ & 47 & 5.32 & 3.17 & 1.59 & 0.57 & 27577 & 3.79 \\
\hline $20-29.99$ & 35 & 3.96 & 2.27 & 1.02 & 0.68 & 23127 & 3.18 \\
\hline $30-39.99$ & 53 & 6.00 & 3.96 & 1.36 & 0.68 & 32547 & 4.48 \\
\hline $40-49.99$ & 41 & 4.64 & 1.93 & 1.47 & 1.25 & 34087 & 4.69 \\
\hline $50-59.99$ & 38 & 4.30 & 2.38 & 1.25 & 0.68 & 26326 & 3.62 \\
\hline $60-69.99$ & 27 & 3.06 & 2.49 & 0.23 & 0.34 & 14656 & 2.02 \\
\hline $70-79.99$ & 35 & 3.96 & 1.25 & 1.13 & 1.59 & 45026 & 6.19 \\
\hline $80-90$ & 44 & 4.98 & 2.15 & 1.81 & 1.02 & 40142 & 5.52 \\
\hline Total & 883 & 100 & 51.19 & 25.25 & 23.56 & 727150 & 100 \\
\hline
\end{tabular}


Table 5. Differences between results in Table 3 and those obtained by Morelli and Piana (2006) with Spot HRV data.

\begin{tabular}{|c|c|c|c|c|c|c|c|}
\hline $\begin{array}{l}\text { Azimuthal } \\
\text { directions }\end{array}$ & $\begin{array}{c}\mathbf{n}^{\circ} \\
\text { lineaments }\end{array}$ & $\begin{array}{c}\% \mathrm{f} \\
\text { azimuthal }\end{array}$ & $\begin{array}{c}\% \mathbf{f} \\
\mathrm{L}<550 \\
\mathrm{~m}\end{array}$ & $\begin{array}{c}\% \text { f } \\
550 \leq \mathrm{L} \leq 1050 \\
\mathrm{~m}\end{array}$ & $\begin{array}{c}\% \mathrm{f} \\
\mathrm{L}>1050 \\
\mathrm{~m}\end{array}$ & $\begin{array}{l}\Sigma \mathbf{L} \\
(\mathbf{m})\end{array}$ & $\begin{array}{r}\% \\
\Sigma \mathrm{L}\end{array}$ \\
\hline $270-279.99$ & 9 & -0.07 & 0.62 & -1.01 & 0.32 & 19411 & 2.50 \\
\hline 280-289.99 & -18 & -3.57 & 0.17 & -2.66 & -1.09 & -17162 & -2.65 \\
\hline $290-299.99$ & -32 & -5.82 & 0.14 & -2.05 & -3.92 & -56998 & -8.38 \\
\hline $300-309.99$ & -3 & -1.95 & 1.01 & -0.83 & -2.13 & -25511 & -3.92 \\
\hline $310-319.99$ & 19 & 0.99 & 1.35 & -0.17 & -0.19 & 553 & -0.17 \\
\hline $320-329.99$ & 38 & 3.61 & 2.57 & 1.17 & -0.12 & 23827 & 3.13 \\
\hline $330-339.99$ & 26 & 2.30 & 1.62 & 0.80 & -0.11 & 16044 & 2.10 \\
\hline $340-349.99$ & 29 & 2.82 & 1.58 & 1.10 & 0.15 & 14705 & 1.92 \\
\hline $350-359.99$ & 3 & -0.45 & 0.29 & 0.02 & -0.74 & 510 & -0.09 \\
\hline $0-9.99$ & 46 & 4.37 & 2.80 & 1.11 & 0.46 & 28563 & 3.80 \\
\hline $10-19.99$ & 23 & 2.01 & 1.70 & 0.57 & -0.26 & 5661 & 0.67 \\
\hline $20-29.99$ & 13 & 0.93 & 0.48 & 0.33 & 0.13 & 5472 & 0.67 \\
\hline $30-39.99$ & 15 & 0.76 & 1.64 & -0.05 & -0.84 & 824 & -0.04 \\
\hline $40-49.99$ & -1 & -1.15 & -1.47 & 0.46 & -0.13 & 5224 & 0.58 \\
\hline $50-59.99$ & -5 & -1.63 & -0.19 & -0.87 & -0.56 & -9745 & -1.51 \\
\hline $60-69.99$ & -10 & -2.04 & -0.21 & -1.20 & -0.62 & -14259 & -2.10 \\
\hline $70-79.99$ & 3 & -0.45 & -0.52 & -0.54 & 0.63 & 20875 & 2.75 \\
\hline $80-90$ & 3 & -0.68 & -0.62 & 0.72 & -0.77 & 6681 & 0.76 \\
\hline Total & 158 & 0.00 & 12.94 & -3.12 & -9.82 & 24676 & 0.00 \\
\hline
\end{tabular}


Table 6. Differences between results in Table 4 and those obtained by Morelli and Piana (2006) with ERS-2 SAR data.

\begin{tabular}{|c|c|c|c|c|c|c|c|}
\hline $\begin{array}{l}\text { Azimuthal } \\
\text { directions }\end{array}$ & $\begin{array}{c}\mathbf{n}^{\circ} \\
\text { lineaments }\end{array}$ & $\begin{array}{c}\% \mathbf{f} \\
\text { azimuthal }\end{array}$ & $\begin{array}{c}\% \mathbf{f} \\
\mathrm{L}<550 \\
\mathrm{~m}\end{array}$ & $\begin{array}{c}\% \text { f } \\
550 \leq \mathrm{L} \leq 1050 \\
\mathrm{~m}\end{array}$ & $\begin{array}{c}\% \mathrm{f} \\
\mathrm{L}>1050 \\
\mathrm{~m}\end{array}$ & $\begin{array}{l}\Sigma \mathbf{L} \\
(\mathbf{m})\end{array}$ & $\begin{array}{c}\% \\
\Sigma \mathrm{L}\end{array}$ \\
\hline $270-279.99$ & 25 & 3.90 & 2.61 & 0.57 & 0.74 & 17250 & 4.66 \\
\hline 280-289.99 & -1 & 1.68 & 1.80 & -0.38 & 0.27 & -10163 & 1.86 \\
\hline $290-299.99$ & -24 & 0.46 & 1.24 & 0.27 & -1.03 & -50136 & -0.42 \\
\hline 300-309.99 & -36 & -0.18 & 1.25 & -0.12 & -1.30 & -67369 & -1.46 \\
\hline $310-319.99$ & -27 & 0.67 & 1.53 & -0.09 & -0.77 & -51855 & -0.66 \\
\hline $320-329.99$ & -34 & 0.17 & 1.00 & -0.35 & -0.46 & -32141 & 0.96 \\
\hline $330-339.99$ & -59 & -2.31 & -0.08 & -1.06 & -1.14 & -57461 & -1.95 \\
\hline $340-349.99$ & -69 & -3.16 & -2.14 & -0.42 & -0.58 & -52968 & -1.75 \\
\hline $350-359.99$ & -85 & -4.84 & -1.39 & -0.61 & -1.36 & -58500 & -2.47 \\
\hline $0-9.99$ & -19 & 1.76 & 0.82 & -0.31 & -0.21 & -33285 & 0.90 \\
\hline $10-19.99$ & -35 & -0.68 & 0.09 & -0.39 & -0.39 & -32551 & -0.78 \\
\hline $20-29.99$ & -44 & -1.84 & 0.00 & -1.18 & -0.64 & -42358 & -1.79 \\
\hline $30-39.99$ & -29 & 0.00 & 2.02 & -0.73 & -1.29 & -45403 & -1.44 \\
\hline $40-49.99$ & -29 & -0.46 & 0.10 & -0.27 & -0.29 & -28189 & -0.04 \\
\hline $50-59.99$ & -27 & -0.50 & 0.90 & 0.07 & -1.45 & -46267 & -1.89 \\
\hline $60-69.99$ & -14 & 0.06 & 1.37 & -0.64 & -0.68 & -26078 & -1.07 \\
\hline $70-79.99$ & 1 & 1.46 & 0.55 & 0.23 & 0.69 & 9853 & 3.52 \\
\hline $80-90$ & 28 & 3.78 & 1.37 & 2.23 & 0.20 & 18484 & 3.88 \\
\hline Total & -478 & 0.00 & 13.03 & -3.19 & -9.70 & -589138 & 0.00 \\
\hline
\end{tabular}

